\section{Nonvisual depth avoidance behavior of infant rats} and mice ${ }^{1}$

RICHARD LORE and MICHAEL LANDAUER, Douglass College, Rutgers-The State University, New Brunswick, N.J. 08903

Three experiments were performed in order to determine whether or not infant rats and mice can employ echolated information to avoid an apparently dangerous fall from an auditory cliff. The results indicate that rodents do not normally use echolocation cues to control the initial exploratory activities that occur just prior to eye opening.

Infant rats can crawl shortly after birth and are able to locomote quite effectively by Day 10, whereas their eyes do not open until they are 14-16 days of age (Blanck, Hard, \& Larsson, 1967; Bolles \& Woods, 1964). During this brief interval, when visual information is unavailable, a number of observations suggest that auditory feedback may play an important role in controlling the young animal's locomotor activities. First, both behavioral and physiological studies indicate that the rat's auditory system becomes functional at about Day 8 or 9 , a time that coincides with the development of locomotor ability (Crowley \& Hepp-Reymond, 1966; Wada, 1923). Secondly, infant rodents produce a variety of noises. The ultrasonic cries emitted by rodents during the preweaning period have attracted a great deal of research interest, but thus far their functional significance is unknown. In both mice and rats, the number of signals suddenly increases on the fourth day of life and then decreases after the eyes open (Noirot, 1966, 1968). Hence, these signals could provide the infant rodent with a biological sonar system comparable to that found in bats. Other noises (e.g., audible cries, teeth clicks, respiratory sounds) could also be used to obtain echolocated information. Adult rats that seldom emit ultrasonic cries can learn to avoid maze obstacles on the basis of auditory feedback (Riley \& Rosenzweig, 1957).

\section{EXPERIMENT 1}

In Experiment 1, the behavior of infant rodents when confronted with auditory "deep" and "shallow" conditions was compared in order to determine if they were capable of avoiding dangerous depths on the basis of auditory cues. Methods

Fifty infant rats of the Long-Evans strain from seven litters were tested when they were 11 days old. The apparatus consisted of a large open-topped box (36 in. high, 20 in. square) with an interior lining of untreated cotton batting ( $2 \mathrm{in}$. thick on the four sides, 6 in. on the bottom). This material has an absorption coefficient that is close to one over a wide range of frequencies. A plywood circular platform (7 in. diam) was mounted in the center and $6 \mathrm{in}$. below the top of the box by means of a wooden dowel affixed to the bottom of the box. For the auditory "deep" condition, a very thin $1 / 2$-in. mesh net was secured 2 in. below the top of the platform. For the auditory "shallow" condition, the net was replaced by a hardboard insert. The net was used to make the response of leaving the platform under the two conditions comparable, while permitting any noises made by the animal to be absorbed by the cotton batting. In the shallow condition, noises made by the animal on the platform would be reflected off the hardboard surface located only $2 \mathrm{in}$. below the top of the platform and thus indicate a relatively safe depth. Each infant rat was given two shallow and two deep trials in random order. A trial ended when the rat made a descent (removed all four feet from the platform) or when 5 min had elapsed. The intertrial interval was approximately $30 \mathrm{sec}$. The experiment was conducted in a sound-attenuation chamber (Industrial Acoustics Model 404-A) to reduce ambient auditory stimulation.

\section{Results}

On the 100 shallow trials, 80 descents were made; on the 100 deep trials, $82 \mathrm{Ss}$ left the platform. Similarly, a comparison of the mean descent latencies (shallow condition $=97.4 \mathrm{sec}$, deep condition $=$ $98.3 \mathrm{sec}$ ) did not approach significance $(t=.45, d f=49, p>.30)$. These results clearly indicate that infant rats do not avoid depth by using information obtained by echolocation. One additional finding of Experiment 1 warrants comment. The mean descent latency over the four trials increased markedly $(\mathrm{F}=12.91, \mathrm{df}=3 / 147$, $\mathrm{p}<.001)$. This finding may be due to a simple fatigue effect since the four trials were given in rapid succession. However, there is the possibility that the increased response latencies represent the rapid acquisition of a passive-avoidance response. In view of the fact that any form of learning has been difficult to demonstrate in very young animals, these results suggest that the neonate rat's capacity to acquire a passive-avoidance response may be better than his capacity to learn other conditioned responses.

\section{EXPERIMENT 2}

The visual cliff has been widely used to measure visual depth avoidance (Walk \& Gibson, 1961). Unlike the technique used in Experiment 1, the visual cliff apparatus permits the animal to make a choice between two simultaneously presented depths-one apparently deep, the other shallow. Strong preferences for shallow-side descents from the device's centerboard indicate that the animal can perceive and will avoid visual depth. It is possible that descent preference between two simultaneously presented depths is a more sensitive measure of depth avoidance than are differences in descent latency between two successively presented depths. Accordingly, in Experiment 2, we designed an "auditory cliff" that would permit infant rats to make a choice between simultaneously presented shallow and deep depths.

\section{Methods}

A centerboard ( 3 in. wide) was mounted 9 in. below the top of the large cotton-lined box used in Experiment 1 . Two inches below one side of the centerboard, thin mesh net was secured to serve as the deep condition. A hardboard insert on the opposite side of the centerboard defined the shallow condition. Four pieces of cord were glued to the surface of the centerboard to reduce slippage and accidental falls.

Ninety-three Long-Evans rats were given two 5-min trials on the auditory cliff when they were 11 days old. Since several animals in the first experiment could not be used because their eyes were partially open by Day 11, flexible collodion was applied to each animal's unopened eyelids on Day 9 to prevent premature eye opening. On each trial, the animal's side preferences and descent latencies were recorded. In addition, the number of times each animal's head protruded over the shallow and deep sides of the centerboard prior to his descent was recorded. This latter measure of the animal's orienting behavior was taken because the side preferences of those animals that have explored both sides of the cliff should be a more sensitive index of depth avoidance.

\section{Results}

Table 1 surnmarizes the results of Experiment 2. On both trials, the Ss made 118 descents. Deep-side descents were made 60 times; the remaining 58 descents were to the shallow side of the auditory cliff. On each trial, those animals that inspected both sides of the cliff at least once before descending did not exhibit a preference for the shallow side of the 
Table 1

Performance of Infant Rats on the Auditory Cliff

\begin{tabular}{|c|c|c|c|c|c|c|}
\hline \multirow[b]{3}{*}{ Exploration } & \multicolumn{6}{|c|}{ Number of Ss Descending } \\
\hline & \multicolumn{3}{|c|}{ Trial 1} & \multicolumn{3}{|c|}{ Trial 2} \\
\hline & Shallow & Deep & $\begin{array}{c}\text { No } \\
\text { Descent }\end{array}$ & Shallow & Deep & $\begin{array}{c}\text { No } \\
\text { Descent }\end{array}$ \\
\hline Shallow and Deep & 28 & 22 & 22 & 14 & 15 & 36 \\
\hline Shallow Only & 8 & 0 & 0 & 4 & 1 & 2 \\
\hline Deep Only & 0 & 12 & 0 & 2 & 9 & 4 \\
\hline No Inspection & 1 & 0 & 0 & 1 & 1 & 4 \\
\hline $\begin{array}{l}\text { Total } \\
\text { Mean Latency (Sec) }\end{array}$ & $\begin{array}{c}37 \\
59.8\end{array}$ & $\begin{array}{c}34 \\
58.6\end{array}$ & 22 & $\begin{array}{c}21 \\
71.0\end{array}$ & $\begin{array}{c}26 \\
73.8\end{array}$ & 46 \\
\hline
\end{tabular}

auditory cliff, whereas those animals that inspected only one side almost invariably descended to that side. Twenty-two Ss failed to make a descent on the first trial, 46 on Trial $2\left(\chi^{2}=8.47, p<.01\right)$. As in the first experiment, the infant $S s$ appear to be learning rapidly to avoid descending. These findings complement the results of the first experiment; infant rodents do not use auditory feedback to avoid an apparently dangerous depth.

\section{EXPERIMENT 3}

Other rodent species may be capable of using auditory feedback to avoid depth. For example, infant mice appear to be better adapted for receiving auditory feedback because their external ears are larger and more anterior than those of rats. In Experiment 3, we examined the auditory cliff performance of infant mice. Methods

Forty-two mixed-strain laboratory mice from six litters were given a single 5 -min trial on the auditory cliff used in Experiment 2. The mice were tested when they were 13 days old after having their eyelids glued shut with collodion on Day 10.

\section{Results}

Only 13 mice left the centerboard. Three descended to the shallow side and 10 chose the deep. Eight of the 13 descending animals inspected both sides of the cliff before making their descent, but only 2 of these chose the shallow side. These data suggest that the auditory cliff performance of infant mice is comparable to that of young rats. Neither species employs echolocated information to avoid an apparently dangerous depth shortly after the auditory system becomes functional. adults can learn to use auditory cues to make crude discriminations after a period of practice. However, the ability is neither well developed nor normally employed when other sensory information is available.

\section{REFERENCES}

BLANCK, A., HARD, E., \& LARSSON, K. Ontogenetic development of orienting behavior in the rat. Journal of Comparative \& Physiological Psychology, 1967, 63, 327-328. BOLLES, R. C., \& WOODS, P. J. The ontogeny of behavior in the albino rat. Animal Behaviour, 1964, 12, 427.441.

No attempt was made to monitor systematically the sound emitted by the animals while they were on the start platform. Informal notes taken during all three experiments indicated that the Ss produced a variety of such audible noises as short-duration cries, teeth clicks, respiratory noises, and footfalls. Thus, it does not seem likely that the infant rodents failed to avoid the deep depths because they produced no sounds.

Further, the chance behavior of the infants could be due to either (1) a failure to discriminate between the two depths, or (2) a lack of fear of depths. The evidence strongly suggests that the fear of depth develops very early in rodents. First, in Experiments 1 and 2, the Ss did appear to learn rapidly to inhibit the response of leaving the platform. Secondly, infant rats reliably avoid the deep side of the visual cliff within $25 \mathrm{~min}$ of eye opening when they are only slightly older (Lore \& Sawatski, 1969).

When given a single trial on a physical cliff located in a darkened room (only auditory cues operative), adult rats also fail to discriminate differences in depth (Lore, Kam, \& Newby, 1967). However, adult rats (Riley \& Rosenzweig, 1957), shrews (Gould, Negus, \& Novick, 1964), and tenrecs (Gould, 1965) can learn to use echolocated information when all other relevant sensory information is eliminated and the $S s$ are given numerous reinforced trials. Taken collectively, these results suggest that the ability of small mammals to use echolocated information is comparable to that of man (Supa, Cotzin, \& Dallenbach, 1944). In these species,
CROWLEY, E. E., \& HEPP-REYMOND, M.CC. Development of cochlear function in the ear of the infant rat. Journal of Comparative \& Physiological Psychology, 1966, 62, 427.432.

GOULD, E. Evidence for echolocation in the Tenrecidae of Madagascar. Proceedings of the American Philosophical Society, 1965, 109 , 352-360.

GOULD, E., NEGUS, N. C., \& NOVICK, A. Evidence for echolocation in shrews. Joumal of Experimental Zoology, 1964, 156, 19-37. LORE, R. K., KAM, B., \& NEWBY, V. Visual and nonvisual depth avoidance in young and adult rats. Journal of Comparative \& Physiological Psychology, 1967, 64, 525-528.

LORE, R. K., \& SAWATSKI, D. Performance of binocular and monocular infant rats on the visual cliff. Joumal of Comparative \& Physiological Psychology, 1969, 70, 566-574. NOIROT, E. Ultra-sounds in young rodents: $I$. Changes with age in albino mice. Animal Behaviour, 1966, 14, 459-462.

NOIROT, E. Ultra-sounds in young rodents: II, Changes with age in albino rats. Animal Behaviour, 1968, 16, 126-134.

RILEY, D. A., \& ROSENZWEIG, $M . R$. Echolocation in rats. Journal of Comparative \& Physiological Psychology, 1957, 50, 323-328.

SUPA, M., COTZIN, M., \& DALLENBACH, K. M. Facial vision: The perception of obstacles by the blind. American Journal of Psychology, 1944, 57, 133-183.

WADA, T. W. Anatomical and physiological studies on the growth of the inner ear of the albino rat. American Anatomical Memoirs, $1923,10,1-74$.

WALK, R. D., \& GIBSON, E. J. A comparative and analytical study of visual depth perception. Psychological Monographs, 1961 , $75(15$, Whole No. 519).

NOTE

1. This study was supported in part by a grant from the Rutgers Research Council and in part by Public Health Research Grant MH-13929 from the National Institute of Mental Health. 